\title{
PERAN PEMANGKU KEPENTINGAN DALAM PELAKSANAAN MODEL DESA KONSERVASI DI TAMAN NASIONAL GUNUNG RINJANI
}

\section{(Role of Stakeholders in the Implementation of Conservation Village Model in Mount Rinjani National Park)}

\author{
Andi Charil Ichsan ${ }^{1}$, Rinekso Soekmadi ${ }^{2}$, Soeryo Adiwibowo ${ }^{3}$ dan Cecep Kusmana ${ }^{4}$ \\ 'Program Studi Kehutanan Universitas Mataram, Jalan Majapahit No 62 Mataram, Indonesia; \\ E-mail: andi.foresta@unram.ac.id \\ ${ }^{2}$ Departemen Konservasi Sumber Daya Hutan dan Ekowisata, Fakultas Kehutanan IPB, \\ Jl. Lingkar Akademik Kampus IPB Dramaga Bogor, Indonesia; \\ E-mail: r.soekmadi@yahoo.co.id \\ ${ }^{3}$ Departemen Sains Komunikasi dan Pengembangan Masyarakat, Fakultas Ekologi Manusia IPB, \\ Jl. Kamper, Kampus IPB Dramaga Bogor, Indonesia; \\ E-mail: sadiwibowo@yahoo.com \\ ${ }^{4}$ Departemen Silvikultur, Fakultas Kehutanan IPB, Jl. Lingkar Akademik \\ Kampus IPB Dramaga Bogor, Indonesia; \\ E-mail: ckmangrove@gmail.com
}

Diterima 29 Januari 2017, direvisi 9 Mei 2017, disetujui 9 Mei 2017

\begin{abstract}
Development of Conservation Village Model (CVM) was expected to enhance the empowerment of communities around the protected area at the Mount Rinjani National Park (MRNP). However, in practice the program did not work optimally. Report on CVM program at MRNP illustrated that the collaboration of CVM management was failed to reach the objective of the program. The objective from this study was to provide an overview regarding the implementation of CVM collaboration at MRNP. This study focused on two villages, Pesanggrahan village and Santong village. The study was carried out from May to July 2016, Data collections were using purposive sampling technique, then analyzed descriptively on the interests and influences of each actor as well as their views on the implementation of CVM. The results showed that the collaborative process undertaken in the development of CVM did not work optimally. MRNP Management Office acted as the central actor in the implementation of CVM, both from the planning to the implementation of the program in the field. Thus, it is necessary to develop a greater collaboration processes which are clear, structured and accountable in encourage the involvement of stakeholders to optimize the implementation of CVM in MRNP.
\end{abstract}

Keyword: Conservation village model; stakeholders; collaboration; Mount Rinjani National Park

\begin{abstract}
ABSTRAK
Pengembangan Model Desa Konservasi (MDK) di Taman Nasional Gunung Rinjani (TNGR) diharapkan dapat meningkatkan keberdayaan masyarakat, namun fakta di lapangan program MDK belum berjalan optimal. Hasil laporan MDK di TNGR juga memberikan gambaran bahwa kolaborasi pengelolaan MDK tidak berjalan dengan baik. Tujuan penelitian ini untuk memberikan gambaran terkait kolaborasi dalam pelaksanaan MDK di TNGR. Penelitian ini difokuskan pada dua desa yaitu Desa Pesangrahan dan Desa Santong. Pelaksanaan penelitian ini dimulai sejak bulan Mei sampai Juli tahun 2016 dengan menggunakan teknik purposive sampling dalam proses pengumpulan datanya. Kemudian data yang terkumpul dianalisis secara deskriptif terkait kepentingan dan pengaruh masing-masing aktor serta pandangannya terhadap pelaksanaan MDK. Hasil penelitian menunjukan bahwa proses kolaborasi yang dijalankan dalam pengembangan MDK belum berjalan optimal. Pihak BTNGR menjadi figur sentral dalam pelaksanaan MDK, baik dari aspek perencanaan sampai pada pelaksanaanya di lapangan. Dengan demikian, diperlukan pengembangan proses kolaborasi yang lebih luas, jelas, terstruktur dalam mendorong keterlibatan stakeholders untuk mengoptimalkan pelaksanaan MDK di TNGR.
\end{abstract}

Kata Kunci: Model Desa Konservasi; stakeholders; kolaborasi; Taman Nasional Gunung Rinjani 


\section{PENDAHULUAN}

Sumber daya hutan merupakan salah satu barang publik yang memerlukan perhatian serius dari stakeholders. Laju kerusakan hutan Indonesia pada rentang waktu 20002009 mencapai 1,5 juta ha/tahun (Forest Watch Indonesia, 2011). Sedangkan untuk empat tahun terakhir yaitu pada tahun 2013, angka deforestasi mencapai 1,13 juta ha/tahun (Forest Watch Indonesia, 2014). Dengan aktifitas penebangan hutan yang tidak terkontrol, konversi lahan dan tata kelola hutan yang buruk, Forest Watch Indonesia (FWI) memperkirakan sisa tutupan hutan Indonesia yang hanya tersisa sekitar 82 juta ha akan terus tergerus dari tahun ketahun.

Kartodihardjo (2006) berpandangan bahwa manfaat langsung hutan dapat dimiliki secara eksklusif oleh pihak pengguna, sementara manfaat tidak langsung menghasilkan sumber daya hutan bersifat tidak terbatas dan dibutuhkan oleh banyak pihak. Manfaat tidak langsung tersebut merupakan barang publik (public property). Hal tersebut ditegaskan oleh Nugroho \& Sukardi (2012), yang mengungkapkan bahwa pemerintah wajib menjamin keberadaan barang publik karena dibutuhkan oleh masyarakat banyak.

Peran masing-masing pihak dalam penggunaan sumber daya hutan menimbulkan interdependensi satu sama lain (Puspitojati, Darusman, Tarumingkeng, \& Purnama, 2012; Wulandari \& Sumarti, 2011; Winara \& Mukhtar, 2011; Massiri, 2016). Hal tersebut memberikan penegasanakan pentingnyaupaya pengelolaan kolaboratif dalam pengelolaan sumber daya hutan, sebagaimana ditegaskan oleh International Union for Conservation of Nature (2003) pentingnya perubahan paradigma pengelolaan kawasan konservasi melibatkan multi pihak yang berkepentingan dan mengakomodasi kepentingan masyarakat setempat.

Pengaturan kelembagaan sebagai mekanisme interaksi antar aktor (Schmid, 2004; Kasper, 1998; Ostrom, 2005), dapat menjadi salah satu instrumen untuk memberikan keadilan manfaat serta mewujudkan keberlanjutan pengelolaan sumber daya hutan.

Saat ini, salah satu upaya yang diterapkan untuk keberlanjutan sumber daya hutan yaitu mengembangkan kelembagaan model desa konservasi (MDK). Secara konseptual MDK merupakan desa yang dijadikan model dalam upaya memberdayakan masyarakat di dalam dan sekitar hutan konservasi dengan memerhatikan aspek sosial, ekonomi, budaya, serta aspek lainnya yang akan menjadi contoh dalam pemberdayaan di tempat lain (Kementerian Kehutanan, 2013). Konsep ini diharapkan dapat meningkatkan keberdayaan masyarakat di sekitar kawasan konservasi, sekaligus sebagai upaya peningkatan pelayanan publik yang diberikan pemerintah kepada masyarakat, dengan harapan bahwa program tersebut dapat diterima dan dirasakan oleh seluruh lapisan masyarakat (Sari, Noor, \& Prasetyo, 2014).

Dalam pelaksanaannya, pengembangan program MDK dilakukan di 133 lokasi (Departemen Kehutanan Republik Indonesia, 2009) termasuk di dalamnya wilayah Taman Nasional Gunung Rinjani khususnya pada wilayah Desa Santong dan Desa Pesangrahan.

Prinsip dalam pengembangan MDK di Taman Nasional Gunung Rinjani (TNGR) didasarkan pada pendekatan paritisipatif dan penerapan pola kemitraan dalam implementasinya. Hal ini sejalan dengan mandat Kementerian Kehutanan (2014) tentang tata cara kerja sama penyelenggaraan kawasan pelestarian alam (KPA) dan kawasan suaka alam (KSA) yang secara tegas memandatkan bahwa kerja sama penyelenggaraan KSA dan KPA sebagai kegiatan bersama stakeholders dibangun atas kepentingan bersama untuk optimalisasi dan efektifitas pengelolaan kawasan atau karena adanya pertimbangan khusus bagi penguatan ketahanan nasional.

Namun, hasil laporan pelaksanaan evaluasi MDK tahun 2014 di TNGR menunjukan 
bahwa saat ini kondisi pelaksanaan MDK sudah tidak lagi berjalan. Beberapa bantuan peralatan yang diberikan sebagai bentuk upaya pemberdayaan saat ini sudah tidak lagi dapat digunakan karena mengalami kerusakan, dan kelembagaan yang dibentuk untuk mengawal pelaksanaan MDK juga sudah tidak lagi berfungsi (Balai Taman Nasional Gunung Rinjani, 2014).

Hasil laporan di beberapa taman nasional lainnya yang menerapkan program MDK seperti Taman Nasional Takabonerate (Effendi, Barkey, Jamil, 2014), Taman Nasional Merapi (Garjita \& Susilowati, 2014), Taman Nasional Gunung Palung (Sepriyanto, Arkanudin, 2012) dan Taman Nasional Gunung Halimun Salak (Pratidna, 2014) juga mendeskripsikan bahwa implementasi program pemberdayaan masyarakat melalui MDK belum berjalan optimal. Beberapa persoalan utama yang muncul, yaitu terkait dengan persoalan kapasitas kelompok yang terbatas serta kolaborasi pengelolaan MDK yang kurang berjalan. Hal tersebut berimplikasi pada insentif dan stimulus yang diberikan belum mampu mengoptimalkan pelaksanaan program.

Dengan demikian fokus penelitian ini bertujuan untuk memberikan gambaran terkait pelaksanaan kolaborasi dalam pelaksanaan MDK di TNGR yang meliputi identifikasi peran masing-masing pemangku kepentingan, mengidentifikasi pengaruh dan kepentingan masing-masing aktor, serta menilai pandangan masing-masing pemangku kepentingan terhadap proses kolaborasi yang selama ini dijalankan. Hal ini penting untuk dilakukan, mengingat salah satu syarat keberhasilan proses kolaborasi, yaitu adanya kesamaan perspektif dalam memaknai tujuan kolaborasi yang dijalankan (Feyerabend, Farvar, Nguinguiri \& Ndangang, 2000).

\section{METODE PENELITIAN}

Penelitian ini dilaksanakan di dua desa sekitar TNGR yang telah ditetapkan sebagai desa pelaksana program MDK, yaitu Desa Pesangrahan, Kabupaten Lombok Timur, dan Desa Santong, Kabupaten Lombok Utara. Penelitian dilaksanakan selama tiga bulan, dimulai dari bulan Mei sampai Juli 2016.

Penelitian ini dirancang dengan menggunakan pendekatan studi kasus yaitu pendekatan yang menguraikan dan menjelaskan secara komprehensif mengenai berbagai aspek yang meliputi individu, kelompok, program, atau suatu situasi sosial, dimana penelitian ini diupayakan untuk menelaah sebanyak mungkin data mengenai subjek yang diteliti, serta menggunakan berbagai instrumen sebagai alat pengumpulan data yang pokok (Mulyana, 2006). Stakeholders atau pemangku kepentingan dalam penelitian ini merupakan individu, kelompok, organisasi, atau institusi yang dapat memengaruhi atau dipengaruhi oleh pelaksanaan MDK.

Informan penelitian ini dipilih dengan menggunakan teknik purposive sampling berdasarkan karakteristik yang dikembangkan oleh Bungin (2007) yaitu informan merupakan orang yang menguasai dan memahami data, informasi, ataupun fakta dari suatu obyek yang diteliti. Informan tersebut merupakan representasi dari Balai Taman Nasional Gunung Rinjani (BTNGR), Sentra Penyuluh Kehutanan Perdesaan (SPKP), pemerintah daerah (Pemda), lembaga swadaya masyarakat (LSM), pemerintah desa, dan tokoh masyarakat.

Analisis yang digunakan dalam penelitian ini mengadopsi model analisis pemangku kepentingan yang dikembangkan (Reed et al., 2009). Analisis pemangku kepentingan ini diterapkan untuk mengungkapkan kepentingan dan pengaruh pemangku kepentingan, memahami sinergi dan konflik antar pemangku kepentingan, dan memahami permintaan pemangku kepentingan terhadap pelaksanaan MDK di TNGR.

Analisis ini dilakukan dengan cara peneliti memberikan penafsiran terhadap 
matriks kepentingan dan pengaruh pemangku kepentingan dalam pelaksanaan MDK di TNGR. Peran dan pengaruh pemangku kepentingan dapat dinilai dengan mengukur besar kecilnya intensitas dan kemampuan pemangku kepentingan tersebut memengaruhi atau memaksa pihak lain untuk mengikuti kemauannya. Sumber pengaruh dapat berupa peraturan, uang, opini, informasi, massa, kepemimpinan dan sebagainya (Asikin, 2001).

Penetapan skoring dilakukan dengan menggunakan daftar pertanyaan untuk mengukur tingkat kepentingan dan pengaruh pemangku kepentingan yang diadopsi dari Roslinda, Darusman, Suharjito \& Nurrochmat (2012) yaitu pengukuran data dengan menggunakan lima gradasi yang disajikan pada Tabel 1. Nilai skor dari lima pertanyaan dijumlahkan dan nilainya dipetakan ke dalam bentuk matriks Analisis Stakeholders (Gambar 1).

Posisi kuadran yang tertuang dalam gambar 1 dapat memberikan pejelasan tentang posisi dan peranan yang dimainkan oleh masing-masing stakeholders terkait dengan pelaksanaan MDK, yang dikategorikan berdasarkan (Reed et al., 2009) adalah sebagai berikut :

Subjects (Kuadran I) merupakan stakeholders yang memiliki kepentingan yang tinggi tetapi pengaruhnya rendah walaupun mereka mendukung kegiatan, kapasitasnya terhadap dampak mungkin tidak ada. Namun

Tabel 1. Skor kepentingan dan pengaruh stakeholders Table 1. Scores of interest and influence stakeholders

\begin{tabular}{llll}
\hline Skor (Score) & Nilai (Value) & Kriteria (Criteria) & \multicolumn{1}{c}{ Keterangan (Information) } \\
\hline \multicolumn{2}{l}{ Tingkat Kepentingan Stakeholders } & & \\
\hline 5 & $21-25$ & Sangat tinggi & Sangat berkepentingan dalam pelaksanaan MDK \\
4 & $16-20$ & Tinggi & Berkepentingan pelaksanaan MDK \\
3 & $11-15$ & Cukup tinggi & Cukup bekepentingan pelaksanaan MDK \\
2 & $6-10$ & Kurang tinggi & Kurang berkepentingan pelaksanaan MDK \\
1 & $0-5$ & Rendah & Tidak berkepentingan pelaksanaan MDK \\
\hline Tingkat Pengaruh Stakeholders & & \\
\hline 5 & $21-25$ & Sangat tinggi & Sangat memengaruhi pelaksanaan MDK \\
4 & $16-20$ & Tinggi & Memengaruhi pelaksanaan MDK \\
3 & $11-15$ & Cukup tinggi & Cukup memengaruhi pelaksanaan MDK \\
2 & $6-10$ & Kurang tinggi & Kurang memengaruhi pelaksanaan MDK \\
1 & $0-5$ & Rendah & Tidak memengaruhi pelaksanaan MDK \\
\hline
\end{tabular}

Sumber (Source) : Roslinda, 2012

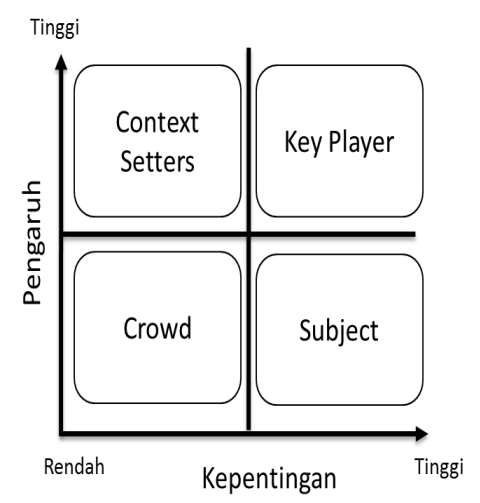

Sumber (Source) : Reed et al., 2009

Gambar 1. Matriks analisis stakeholders

Figure 1. Stakeholder analysis matrix 
dapat menjadi pengaruh jika membentuk aliansi dengan stakeholders lainnya.

Key Players (Kuadran II) merupakan stakeholders yang aktif karena mereka mempunyai kepentingan dan pengaruh yang tinggi terhadap pengembangan suatu proyek.

Crowd (Kuadran III) merupakan stakeholders yang memiliki sedikit kepentingan dan pengaruh terhadap hasil yang diinginkan dan hal ini menjadi pertimbangan untuk mengikutsertakannya dalam pengambilan keputusan.

Context Setters (Kuadran IV) memiliki pengaruh yang tinggi tetapi sedikit kepentingan, oleh karena itu, mereka dapat menjadi resiko yang signifikan untuk harus dipantau.

Kemudian, analisis dilanjutkan dengan mengidentifikasi pandangan masing-masing pihak terkait dengan proses kolaborasi yang dilakukan dalam pelaksanaaan MDKdiTNGR. Dalam analisis ini, kerangka yang digunakan mengadaptasi kriteria proses kolaborasi dari (Conley, 2003) yang menyebutkan bahwa proses kolaborasi dapat dilihat dari beberapa kriteria diantaranya sebagai berikut : 1) Adanya visi bersama, 2) Tujuan yang jelas dan layak, 3) Partisipasi inklusif stakeholders, 4) Partisipasi pemerintah daerah, 5) Terbuka, mudah diakses, dan proses yang transparan, 6) Perencanaan jelas dan tertulis, 7) Pengambilan keputusan berdasarkan konsensus.

\section{HASIL DAN PEMBAHASAN}

Penelitian ini memberikan gambaran mengenai tingkat pengaruh dan kepentingan serta pandangan masing-masing aktor terhadap proses kolaborasi yang di jalankan dalam pelaksanan MDK. Secara detail mengenai temuan temuan tersebut dapat dilihat pada uraian dibawah ini :

\section{A. Identifikasi Kepentingan dan Pengaruh Masing-masing Aktor dalam MDK}

Aktor-aktor yang terlibat langsung dalam pelaksanaan MDK di TNGR adalah Balai Taman Nasional Gunung Rinjani (BTNGR), kelompok masyarakat di Desa Santong yang dibentuk oleh BTNGR yaitu Sentra Penyuluh Kehutanan Pedesaan Rinjani Tiu Teja (SPKP RTT), kelompok masyarakat yang berada di Desa Pesangrahan yang dibentuk oleh TNGR yaitu Sentra Penyuluh Kehutanan Pedesaan Sadar Lestari (SPKP SL), Pemerintah Desa Santong dan Pemerintah Desa Pesangrahan. Masing masing aktor memiliki kepentingan dan pengaruh yang berbeda terhadap keberadaan program MDK, begitu pula dengan kekuasaan yang dimilikinya. Perbedaan kepentingan dan pengaruh antar aktor bisa menjadi sumber konflik dalam pengelolaan suatu wilayah, karena masing-masing aktor berusaha memanfaatkan kekuasaan yang dimiliki untuk mendapatkan kepentingannya (Febriyano, 2014)

Secara umum bentuk intervensi yang dilakukan dalam kerangka pelaksanaan MDK di lapangan meliputi pemberian sejumlah bantuan seperti peralatan pengolah air minum isi ulang, pengolah kopi, pengolah keripik, bantuan alat perkemahan dan perlengkapan sablon. Selain pemberian bantuan, pihak BTNGR juga menyelenggarakan beberapa pelatihan dalam kerangka pengembangan MDK. Adapun pihak-pihak yang terlibat dan perannya dalam pelaksanaan MDK di kedua wilayah tersebut dapat dilihat pada Tabel 2.

Tabel 2. Lembaga dan perannya dalam pelaksanaan MDK Table 2. Institutions and its role in the implementation of MDK

Lembaga (Institution)
Peran dalam MDK (Role In MDK)

BTNGR
1. Sebagai pelaksana program dari pusat

2. Menentukan penetapan lokasi sasaran program

3. Merencanakan kegiatan dalam pelaksanaan program

4. Melaksanakan monitoring terhadap pelaksanaan prorgam 


\begin{tabular}{|c|c|}
\hline Lembaga (Institution) & Peran dalam MDK (Role In MDK) \\
\hline Kelompok SPKP RTT-Santong & Sebagai pelaksana prorgam MDK di Desa Santong \\
\hline Kelompok SPKP-SL-Pesangrahan & Sebagai pelakasana program MDK di desa Pesangrahan \\
\hline $\begin{array}{lll}\text { Pemerintah Desa } & \text { (Pemdes) } \\
\text { Pesangrahan } & & \\
\end{array}$ & $\begin{array}{l}\text { 1. Sebagai tempat serah terima barang bantuan MDK } \\
\text { 2. Mengikuti pertemuan terkait program TNGR }\end{array}$ \\
\hline Pemerintah Desa (Pemdes) Santong & $\begin{array}{l}\text { 1. Diminta oleh BTNGR untuk bertindak sebagai pembina MDK } \\
\text { berdasarkan MOU antara BTNGR dengan SPKP tahun } 2010 \\
\text { 2. Sebagai tempat penyaluran distribusi bantuan }\end{array}$ \\
\hline
\end{tabular}

Sumber (Source): Data primer/diolah (Primary data/processed)

Program MDK tidak banyak melibatkan pihak-pihak terkait seperti pemerintah daerah, LSM dan mitra lainnya yang selama ini juga melakukan kegiatan di wilayah yang sama. Kurangnya keterlibatan aktor lain dalam pelaksanaan MDK ini didasarkan pada beberapa alasan seperti yang diungkapkan Petugas BTNGR yaitu :

"Kami hanya menjalankan tugas pelaksanaan dari pusat, untuk koordinasi dengan pihak lainnya yang kami harap lembaga lainya juga melaksanakan tugas dan fungsinya masingmasing, seperti kalau kami sudah memberikan bantuan peralatan usaha ke kelompok seharusnya ditindaklanjuti dengan pendampingan dari dinas terkait di daerah atau lembaga mitra lainnya, karena kemampuan kami juga terbatas"

Berdasarkan hasil diskusi dengan pihak pemerintah daerah terkait dalam hal ini, Pak Teguh dari Dinas Kehutanan Provinsi Nusa Tenggara Barat (NTB) menyebutkan bahwa :

"Selama ini kami tidak ada koordinasi terkait dengan kegiatan MDK, yang ada hanya koordinasi terkait dengan pengamanan kawasan hutan saja"

Hal tersebut diperkuat oleh argumentasi direktur Yayasan Masyarakat Nusa Tenggara (SAMANTA) yang menyebutkan bahwa :

"Selama ini taman nasional cenderung jalan sendiri, banyak kegiatan yang kami tidak ketahui termasuk MDK itu, padahal kami juga sering beraktivitas di sekitar kawasan hutan konservasi termasuk di Desa Santong dalam rangka fasilitasi perizinan HKM"

Sejalan dengan apa yang diungkapkan Direktur SAMANTA, koordinator WWF Nusa Tenggara juga mengungkapkan bahwa : "Selama ini untuk pelaksanaan MDK tidak ada koordinasi terkait hal itu, padahal kami sangat intensif bekerja sama dengan BTNGR dalam hal program-program lain seperti rehabilitasi dan beberapa kegiatan penelitian di TNGR"

Argumentasi masing-masing aktor tersebut menujukan adanya asimetris informasi terkait dengan pelaksanaan MDK di lapangan. Dimana lembaga-lembaga mitra lainnya tidak mengetahui dan tidak pernah dikoordinasikan tentang pelaksanaan prorgam MDK tersebut, sehingga mereka tidak terlibat di dalamnya. sementara di sisi lain, pihak BTNGR berharap adanya dukungan dari pihak lain untuk membantu pelaksanaan MDK di lapangan karena mereka menyadari bahwa untuk mengoptimalkan program tersebut dibutuhkan dukungan dari berbagai pihak mulai dari instansi teknis maupun lembaga mitra lainnya. Seperti yang ditegaskan Kepala Seksi Wilayah 1 BTNGR :

"Selama ini kegiatan pemberdayaan dirasakan kurang maksimal, karena beberapa alasan. Selain terkendala anggaran dan kapasitas, kami juga terbatas dalam hal jumlah personil. Seperti di Seksi Wilayah I Lombok Utara, dimana tugas pemberdayaan masyarakat diserahkan kepada satu orang penyuluh kehutanan dan harus melakukan pendampingan di 16 desa yang berada di wilayah Seksi I ini”.

Namun demikian, kebutuhan-kebutuhan ini kurang terkoordinasikan, karena belum ada pihak yang secara intensif membuka ruang komunikasi terhadap kebutuhan strategis tersebut, termasuk pihak BTNGR.

Di sisi lain, masing-masing aktor yang terlibat dalam pelaksanaan MDK memiliki tingkat kepentingan berbeda, hal ini dapat 
Tabel 3. Tingkat kepentingan stakeholders dalam pelaksanaan MDK di TNGR Table 3. Stakeholders interest level in the implementation of MDK in TNGR

\begin{tabular}{|c|c|c|c|c|c|c|c|}
\hline \multirow[t]{2}{*}{ No } & \multirow{2}{*}{$\begin{array}{c}\text { Pemangku Kepentingan } \\
\text { (Stakeholders) }\end{array}$} & \multicolumn{5}{|c|}{ Kepentingan (Intrest) } & \multirow{2}{*}{$\begin{array}{l}\text { Nilai } \\
\text { (Value) }\end{array}$} \\
\hline & & $\mathbf{K 1}$ & $\mathbf{K 2}$ & $\mathbf{K 3}$ & K4 & $\mathbf{K 5}$ & \\
\hline 1 & BTNGR & 5 & 4 & 4 & 3 & 5 & 21 \\
\hline 2 & SPKP-RTT Santong & 4 & 4 & 1 & 4 & 5 & 18 \\
\hline 3 & Pemdes Santong & 5 & 4 & 2 & 3 & 5 & 19 \\
\hline 4 & Pemdes Pesangrahan & 5 & 2 & 2 & 3 & 5 & 17 \\
\hline 5 & SPKP-SL & 5 & 5 & 1 & 5 & 1 & 17 \\
\hline
\end{tabular}

Keterangan (Information) : K1 = Persepsi pentingnya pelaksanaan MDK; K2 = Keterlibatan pemangku kepentingan terhadap pelaksanaan MDK; K3 = Program pemangku kepentingan terkait pelaksanaan MDK; K4 = Manfaat MDK bagi pemangku kepentingan; K5 = Ketergantungan pemangku kepentingan terkait pelaksanaan MDK.

Sumber (Source): Data primer/diolah (Primary data/processed).

dilihat dari pandangan masing-masing aktor terkait dengan MDK, bentuk keterlibatan, alokasi program, besaran manfaat yang diterima oleh masing masing aktor. Secara detail mengenai tingkat kepentingan masingmasing aktor tersebut dapat dilihat pada Tabel 3.

Hasilpemetaankepentinganmasing-masing aktor, menunjukan bahwa selama ini pihak BTNGR memiliki kepentingan yang paling besar dalam pelaksanaan MDK di lapangan. Hal ini didasari dari adanya argumentasi yang menyebutkan bahwa program MDK merupakan salah satu media bagi pengelola TNGR untuk memberdayakan masyarakat di sekitar kawasan konservasi. Untuk itu, pihak BTNGR akan terus mengusahakan berbagai program pemberdayaan masyarakat meskipun dalam prakteknya intervensiintervensi tersebut banyak yang tidak berjalan sesuai dengan harapan pengelola TNGR. Berbeda halnya dengan Pemerintah
Desa Pesangrahan meskipun menganggap MDK penting tetapi selama ini pihak desa kurang dilibatkan dalam pelaksanaan MDK sendiri. Selama ini keterlibatan pihak desa dalam pelaksanaan MDK hanya sebatas sebagai tempat menyerahkan bantuan dari BTNGR kepada kelompok dalam kerangka pelaksanaan MDK. Seperti yang diungkapkan pihak Desa Pesangrahan sebagai berikut :

"Jika BTNGR akan menyerahkan bantuan, di saat itu BTNGR menghubungi kami untuk meminta difasilitasi tempatnya, setelah itu tidak ada komunikasi lebih lanjut".

Di sisi lain, identifikasi pengaruh masingmasing aktor dalam pelaksanaan MDK di TNGR juga berbeda-beda tergantung dari kewenangan masing-masing aktor serta kontribusi yang diberikan dalam program MDK di TNGR. Secara detail mengenai gambaran umum pengaruh masing-masing aktor (pemangku kepentingan) dalam pelaksanaan MDK di TNGR dapat dilihat pada Tabel 4 berikut :

Tabel 4. Tingkat pengaruh stakeholder dalam pelaksanaan MDK di TNGR Table 4. Stakeholder influence level in the implementation of MDK in TNGR

\begin{tabular}{|c|c|c|c|c|c|c|c|}
\hline \multirow[t]{2}{*}{ No } & \multirow{2}{*}{$\begin{array}{c}\text { Pemangku Kepentingan } \\
\text { (Stakeholders) }\end{array}$} & \multicolumn{5}{|c|}{ Pengaruh (Power) } & \multirow{2}{*}{$\begin{array}{l}\text { Nilai } \\
\text { (Value) }\end{array}$} \\
\hline & & P1 & $\mathbf{P 2}$ & P3 & P4 & P5 & \\
\hline 1 & BTNGR & 4 & 5 & 5 & 5 & 5 & 24 \\
\hline 2 & SPKP RTT Santong & 4 & 4 & 1 & 1 & 4 & 14 \\
\hline 3 & Pemdes Santong & 1 & 1 & 1 & 2 & 5 & 10 \\
\hline 4 & Pemdes Pesangrahan & 1 & 1 & 1 & 1 & 5 & 9 \\
\hline 5 & SPKP-SL & 4 & 2 & 2 & 1 & 5 & 15 \\
\hline
\end{tabular}

Keterangan (Information) : P1= Kemampuan pemangku kepentingan memperjuangkan aspirasinya terkait MDK; P2 = Kontribusi fasilitas yang diberikan oleh pemangku kepentingan terkait MDK; P3= Kapasitas kelembagaan/ SDM yang ditugaskan oleh pemangku kepentingan terkait MDK; P4 = Dukungan anggaran pemangku kepentingan yang digunakan untuk MDK; P5 = Kebutuhan kerja sama dalam pelaksanaan MDK.

Sumber (Source): Data primer/diolah (Primary data/processed) 
Dari hasil analisis mengenai tingkat pengaruh masing-masing aktor terhadap pelaksanaan MDK di TNGR dapat digambarkan bahwa aktor yang paling memiliki pengaruh terhadap pelaksanaan MDK adalah Balai TNGR. Hal ini diketahui dari besaran alokasi anggaran dan ketersediaan tenaga yang dialokasikan untuk pelaksanaan program tersebut. Sedangkan untuk aktor lainnya seperti pemerintah desa dan SPKP hampir tidak ada alokasi anggaran dan program yang dikhususkan untuk mendukung pelaksanaan MDK tersebut.

\section{B. Klasifikasi Pemangku Kepentingan (Stakeholders) dalam Pelaksanaan MDK di TNGR}

Berdasarkan data pengaruh dan kepentingan masing masing aktor yang terlibat dalam pelaksanaan MDK, maka aktor-aktor tersebut dapat diklasifikasikan berdasarkan kerangka analisis yang dikembangkan oleh Reed et al. (2009) dengan membagi klasifikasi stakeholders ke dalam empat kuadran yaitu Subjects, Key Players, Crowd dan Context Setters. Secara detail mengenai pembagian aktor yang teribat dalam pengembangan MDK di TNGR dapat dilihat pada Gambar 2 berikut:
Hasil klasifikasi para aktor berdasarkan kerangka yang dikembangkan oleh Reed et al. (2009) dapat diketahui bahwa konsentrasi aktor terbagi dalam dua kuadran yaitu subject dan key players, dimana dari lima aktor yang teridentifikasi hanya satu aktor yang masuk dalam kategori key players yaitu BTNGR. Sementara itu, untuk aktor lainnya terkonsentrasi pada kuadran subjects, karena meskipun memiliki kepentingan yang besar terhadap pelaksanaan MDK, namun mereka tidak memiliki pengaruh yang kuat terhadap pelaksanaan program tersebut. Hal ini dapat dilihat dari kurangnya kontribusi, alokasi sumber daya serta kewenangan yang dimiliki pemerintah desa dan SPKP dalam pelaksanaan MDK di lapangan.

Melalui program MDK, pihak BTNGR telah menetapkan lokasi yang menjadi sasaran pelaksanaan program juga menyusun rencana intervensi programnya mulai dari membentuk keompok, melakukan pelatihan sampai pada mendistribusikan bantuan peralatan sesuai dengan permintaan kelompok masyarakat.

Peran sentral pihak BTNGR dalam pelaksanaan MDK tidak bisa di pisahkan dari bentuk intervensi yang selama ini diberikan TNGR dalam pelaksanaan MDK. Hal ini berakibat pada tingginya tingkat

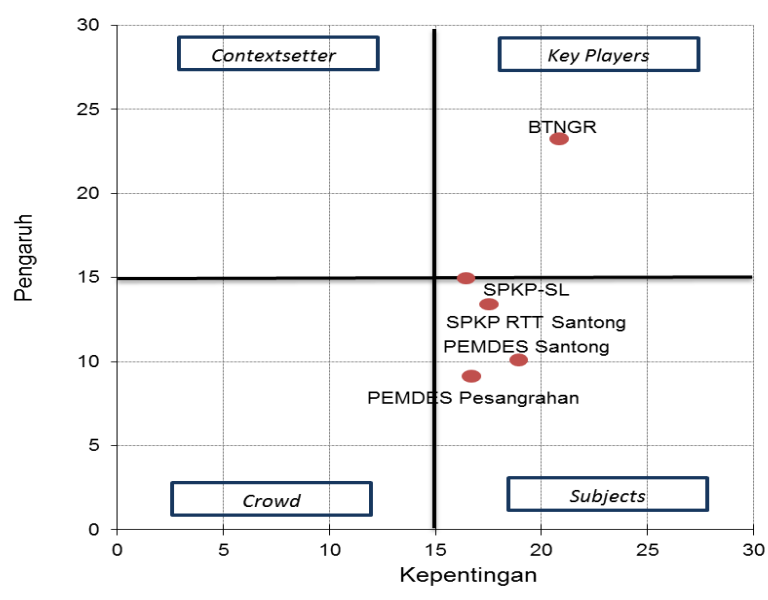

Sumber (Source): Data primer/diolah (Primary data/processed)

Gambar 2. Klasifikasi stakeholders dalam pelaksanaan MDK di TNGR

Figure 2. Classification of stakeholders in the implementation of MDK in TNGR 
ketergantungan kelompok terhadap BTNGR dalam pelaksanaan MDK.

\section{Multi Interpretasi Stakeholders terkait dengan Kolaborasi Pelaksanaan MDK di TNGR}

Pada umumnya kolaborasi merupakan proses yang mendasar dari bentuk kerja sama yang melahirkan kepercayaan, integritas dan terobosan melalui pencapaian konsensus, keterpaduan pada semua aspek organisasi (Lembaga Administrasi Negara, 2008).. Dengan demikian, kata kunci dari proses kolaborasi sesungguhnya terletak pada bagaimana keterpaduan itu dibangun dan dijalankan oleh aktor-aktor yang terlibat. Hasil penelitian menunjukan pandangan masing-masing aktor terkait dengan proses kolaborasi yang dijalankan selama ini cukup beragam baik dari kriteria adanya visi bersama, kejelasan tujuan, partisipasi dalam kegiatan, keterbukaan dalam proses dan lainnya. Secara detail mengenai pandangan aktor terkait dengan proses kolaborasi pelaksanaan MDK di TNGR diuraikan sebagai berikut :

\section{Balai Taman Nasional Gunung Rinjani (BTNGR)}

Pihak BTNGR memberikan pandangan bahwa selama ini proses yang dilakukan didasarkan atas visi bersama yaitu mendorong hutan lestari masyarakat sejahtera. Sebelum program ini dijalankan, terlebih dahulu dilakukan pelatihan kepada masyarakat agar mayarakat bisa memahami tujuan dan maksud dari pelaksanaan program tersebut. Dari sisi partisipasi masyarakat, selama ini proses yang dilakukan selalu dikonsultasikan dengan masyarakat termasuk dalam hal penyusunan program dan pengambilan keputusan sehingga prosesnya juga cukup terbuka. Dalam pelaksanaaan MDK di TNGR selama ini keterlibatan pemerintah daerah dirasakan sangat kurang padahal peran mereka sangat dibutuhkan, hal ini dapat dilihat dari tidak adanya dukungan dan kerja sama yang di berikan oleh dinas dinas terkait dalam mendukung pelaksanaan MDK dilapangan.

\section{Pemerintah Desa Santong}

Selama ini Pemerintah Desa Santong kurang mengetahui secara detail terkait dengan visi dan tujuan penyelenggaraan MDK di desa mereka. Pihak desa hanya sebatas mengikuti beberapa pertemuan yang dilakukan oleh kelompok. Sementara untuk perencanaan kegiatan, disusun langsung oleh kelompok, pihak desa kurang mengetahui bentuk kegiatannya seperti apa karena kurangnya koordinasi dari kelompok.

Pihak desa juga menyampaikan bahwa dalam pelaksanaan MDK di Desa Santong, peran dari pemerintah daerah seperti dinas terkait masih dirasakan sangat kurang karena kegiatan hanya dikoordinasikan dengan pihak BTNGR saja. Selama ini pihak desa mengharapkan agar pemerintah kabupaten melalui satuan kerja perangkat daerah (SKPD) terkait ikut memberikan dukungan dalam bentuk pendampingan dan pembinaan teknis terhadap kelompok-kelompok MDK agar dapat meningkatkan kualitas produksi dan jaringan pemasarannya.

\section{Kelompok SPKP-RTT Santong}

Pelaksanaan MDK memiliki visi dan tujuan yang jelas yaitu untuk memberdayakan masyarakat desa. Selama ini pelaksanaan kegiatan MDK berjalan terbuka dan partisipatif dengan mengundang pihak desa dan kepalakepala dusun setempat untuk menentukan program yang akan dijalankan. Dalam proses pengambilan keputusan, program MDK juga dilakukan berdasarkan kesepakatan bersama anggota kelompok. Selama ini kelompok sudah memiliki dokumen perencanaan dalam bentuk roadmap pelaksanaan MDK, namun dalam implementasinya dokumen tersebut tidak bisa direalisasikan karena kurangnya dukungan dari pihak terkait khususnya pemerintah daerah. Koordinasi hanya dilakukan dengan pihak BTNGR sebagai penggagas program. 


\section{Pemerintah Desa Pesangrahan}

Selama ini dalam pelaksanaan MDK, pemerintah desa kurang terlibat baik dari sisi perencanaan, pelaksanaan sampai pada evaluasi program. Secara umum pemerintah desa tidak mengetahui secara detail terkait visi, tujuan dan perencanaan MDK di desa mereka. Pelaksanaan MDK langsung dikoordinasikan oleh kelompok dengan TNGR. Desa hanya berperan sebagai tempat serah terima barang bantuan MDK. Pihak TNGR maupun kelompok kurang melibatkan pemerintah desa dalam kegiatan SPKP, pihak desa juga tidak pernah menerima salinan dokumen perencanaan kelompok SPKP dalam pelaksanaan MDK.

\section{Kelompok SPKP-SL Pesangrahan}

Kelompok SPKP-SL memberikan gambaran bahwa pelaksanaan MDK di desa mereka merupakan salah satu media untuk memberdayakan masyarakat di sekitar kawasan konservasi. Namun demikian, dalam pelaksanaan MDK kelompok SPKP tidak memiliki mekanisme kelembagaan yang memadai (mekanisme pembagian peran dan tanggung jawab, mekanisme monitoring dan evaluasi serta penegakan sanksi), kelompok jarang mendapatkan pembinaan dari pihak BTNGR dalam pelaksanaan MDK. Dari sisi paritisipasi kelompok, selama ini keterlibatan anggota kelompok masih sangat minim dari 22 anggota kelompok dan hanya 5 orang yang aktif dalam kelompok SPKP. Proses pengambilan keputusan dalam kelompok hanya didasari kesepakatan anggota aktif, tidak didasarkan pada kesepakatan yang dibangun antara pihak kelompok dengan pihak desa maupun lembaga mitra lainnya.

Dari pandangan masing-masing aktor di atas, dapat digambarkan bahwa terdapat perbedaan pandangan pada masing-masing aktor dalam memaknai proses kolaborasi yang dijalankan dalam pelaksanaan MDK. Secara umum perbedaan pandangan tersebut disajikan pada Tabel 5 dibawah ini :

Selama ini pelaksanaan MDK di Desa Santong dikoordinasikan langsung oleh BTNGR kepada kelompok, sedangkan pihak desa hanya bertindak sebagai penyedia fasilitas dan memberikan arahan kepada kelompok. Sedangkan untuk Desa Pesangrahan pelaksanaan MDK kurang melibatkan pemerintah desa, dan hanya

Tabel 5. Pandangan aktor terhadap kolabaorasi pelaksanan MDK di TNGR

Table 5. Actor outlook about MDK collaboration implementation in TNGR

\begin{tabular}{|c|c|c|c|c|c|}
\hline $\begin{array}{c}\text { Kriteria Proses kolaborasi } \\
\text { (Collaboration Proces Criteria) }\end{array}$ & $\begin{array}{l}\text { BTNGR } \\
(M R N P)\end{array}$ & $\begin{array}{l}\text { Pemdes Santong } \\
\text { (Santong village) }\end{array}$ & $\begin{array}{c}\text { SPKP - } \\
\text { RTT } \\
\text { (SPKP } \\
\text { RTT } \\
\text { Group) }\end{array}$ & $\begin{array}{c}\text { Pemdes } \\
\text { Pesangrahan } \\
\text { (Pesangrahan } \\
\text { village) } \\
\end{array}$ & $\begin{array}{c}\text { SPKP- } \\
\text { SL } \\
\text { (SPKP- } \\
\text { SL } \\
\text { Group) }\end{array}$ \\
\hline $\begin{array}{l}\text { Adanya visi bersama pelaksanaan } \\
\text { MDK }\end{array}$ & V & $?$ & $\mathrm{~V}$ & $?$ & \\
\hline Tujuan yang jelas dan layak & V & $?$ & V & $?$ & $?$ \\
\hline partisipasi inklusif stakeholders & V & $\nabla$ & V & $\mathrm{X}$ & $\mathrm{X}$ \\
\hline Partisipasi pemerintah daerah & $\mathrm{X}$ & $\mathrm{X}$ & $\mathrm{X}$ & $\mathrm{X}$ & $\mathrm{X}$ \\
\hline $\begin{array}{l}\text { Terbuka, mudah diakses, dan } \\
\text { proses yang transparan }\end{array}$ & $\mathrm{V}$ & $\mathrm{X}$ & V & $?$ & $\mathrm{~V}$ \\
\hline Perencanaan jelas dan tertulis & V & $\mathrm{X}$ & $\nabla$ & $\mathrm{X}$ & $\mathrm{X}$ \\
\hline $\begin{array}{l}\text { Pengambilankeputusan } \\
\text { berdasarkan konsensus }\end{array}$ & V & $?$ & V & $?$ & V \\
\hline
\end{tabular}

Sumber (Source): Data primer/diolah (Primary data/processed) 
menjadikan kelompok sebagai sarana untuk mendistribusikan bantuan tanpa memerhatikan aspek kelembagaan dan dinamika dalam kelompok. Sebagaimana yang diungkapkan oleh Tokoh Masyarakat Desa Pesangrahan yang menyebutkan bahwa :

"Ketika bantuan dari pusat itu ada, mereka secara aktif membentuk kelompok walaupun secara instan, ketika tidak ada proyek atau tidak ada bantuan, mereka tidakpeduli dengan keberadaan kami, itulah yang terjadi pada kami. Sehingga kami merasa dimanfaatkan Kalaupun ada yang keberatan sekarang berani saya ajak debat, karena kenyataannya seperti itu ketika bantuan itu tidak ada kami tidak diperdulikan lagi dianggap seperti tidak ada"

Di sisi lain, terungkap bahwa keterlibatan pemerintah daerah dan mitra lainnya dalam pelaksanan MDK di kedua desa masih sangat rendah. Hal ini dikarenakan kurangnya koordinasi yang dilakukan oleh pihak BTNGR maupun kelompok dalam penyelenggaraan MDK.

Suporahardjo (2005) mengingatkan bahwa sebaiknya para aktor yang mengusahakan suatu kolaborasi untuk mengantisipasi dan membuat evaluasi atas kemampuannya mengatasi kenyataan dan potensi kendalakendala yang mungkin dihadapinya. Salah satu kondisi yang menyebabkan tingkat keberhasilannya rendah, yaitu ketika suatu stakeholders mempunyai power untuk melakukan aksi sepihak.

Wollenberg, Edmunds, Buck, Fox \& Brodt (2005) mengutarakan pengelolaan hutan secara kolaboratif saja, tidak mampu secara efektif membawa pengetahuan dan kapasitas kelompok yang berbeda tersebut. Koordinasi yang terjadi antar kelompok kepentingan lebih lemah dari pada yang diharapkan.

Pengelolaan kolaboratif bisa membaik jika para pengambil keputusan memerhatikan aspirasi pemangku kepentingan yang berkepentingan dengan pelaksanaan program (Herawati, Widjayanto, Saharuddin, \& Eriyatno, 2010). Kolaborasi juga dapat ditingkatkan dengan menjamin bahwa tidak ada pandangan atau pengetahuan dari satu kelompokpun yang mendominasi pada proses ini. Hal tersebut juga ditegaskan oleh Feyerabend et al., (2000) yang mengungkapkan bahwa kolaborasi harus mampu menjamin pembagian yang adil (fair sharing) dari masing-masing pihak terhadap fungsi manajemen, pembagian hak dan tanggung jawab pada wilayah/arena tertentu atau sumber daya alam.

\section{KESIMPULAN DAN SARAN}

\section{A. Kesimpulan}

Bentuk pemberdayaan yang cenderung bersifat mendistribusikan bantuan dalam pelaksanaan MDK, berimplikasi pada munculnya berbagai persoalan dalam pelaksanaan MDK itu sendiri. Hasil penelitian menunjukkan bahwa selama ini pihak BTNGR bertindak sebagai figur sentral dalam pelaksanaan MDK.

Ruang-ruang kolaborasi yang tersedia tidak termanfaatkan dengan baik melalui proses komunikasi dan koordinasi yang intensif dengan pihak pihak yang terlibat. Hal tersebut berdampak pada adanya ketidaksamaan pandangan dari masing masing aktor dalam memaknai proses kolaborasi yang dijalankan. Selama ini proses kolaborasi yang dibangun cenderung bersifat eksklusif antara pihak BTNGR dengan kelompok masyarakat yang menjadi sasaran program, sehingga tidak jarang menimbulkan kesalahpahaman diantara aktor-aktor yang terlibat lainnya Di sisi lain, belum ada mekanisme kolaborasi yang dibangun dengan stakeholders yang lebih luas dalam kerangka pengembangan MDK tersebut.

\section{B. Saran}

Pemberdayaan dalam kerangka MDK memerlukan upaya yang lebih komprehensif dari berbagai pihak, mulai dari mempersiapkan kondisi iklim yang mampu mendorong motivasi masyarakat, meningkatkan kapasitas danjejaringkerja samanya serta mengusahakan 
proses kolaborasi yang lebih luas, jelas, terstruktur dan terbuka dengan aktor-aktor potensial lainnya. Dengan demikian proses kolaborasi yang dibangun dapat dipahami dan dijalankan secara konsisten oleh pihak-pihak yang berkepentingan.

\section{UCAPAN TERIMA KASIH}

Penelitian ini tidak lepas dari dukungan berbagai pihak yang turut membantu memberikan masukan, saran serta pertimbangan yang konstruktif terhadap proses penelitian. Untuk hal tersebut, penulis mengucapkan terima kasih kepada WWF Nusa Tenggara, Balai Taman Nasional Gunung Rinjani, Pak Haji Badrun, Pak Haji Artim, Zainuddin, Pak Karti, Pak Sabidi, Masyarakat Desa Santong dan Desa Pesangrahan atas kontribusinya selama penelitian berlangsung.

\section{DAFTAR PUSTAKA}

Asikin, M. (2001). Stakeholders: Participation in SME policy design and implementation. Jakarta Indonesia: ADB technical assistance SME development.

Balai Taman Nasional Gunung Rinjani.(2014). Laporan monitoring dan evaluasi pelaksanaan model desa konservasi di Desa Santong. Mataram: Balai Taman Nasional Gunung Rinjani.

Bungin, B. (2007). Penelitian kualitatif: Komunikasi, ekonomi, kebijakan publik, dan ilmu sosial. Jakarta: Kencana Prenama Media Group.

Conley, A (2003). Evaluating collaborative natural resource management. Society and Natural Resources, 16, 371-386.

Departemen Kehutanan Republik Indonesia. (2009). Laporan pelaksanan model desa konservasi tahun 2009. Jakarta: Departemen Kehutanan Republik Indonesia.

Effendi, A.D., Barkey, R.A., Jamil, M.H. (2014). Strategi pengembangan program pemberdayaan masyarakat pada model desa konservasi di Taman Nasional Taka Bonerate. Jurnal Sains \& Teknologi, 14(2), 151-161.

Febriyano, I.G. (2014). Politik ekologi pengelolaan mangrove di Kabupaten Pesawaran Provinsi Lampung. (Disertasi). Bogor: Institut
Pertanian Bogor.

Feyerabend, G.B., Farvar, M.T., Nguinguiri, J.C., Ndangang, V.A. (2000). Co-management of natural resources: Organising, negotiating and learning by-doing. Kasparek Verlag, Heidelberg (Germany): GTZ and IUCN.

Forest Watch Indonesia. (2011). Potret keadaan hutan Indonesia periode tahun 2000-2009 (Edisi Pertama). Bogor: Forest Watch Indonesia.

Forest Watch Indonesia. (2014). Potret keadaan hutan Indonesia periode tahun 2009-2013. Bogor: Forest Watch Indonesia.

Garjita, I.P., Susilowati, I.S.T. (2014). Strategi pemberdayaan masyarakat kelompok tani hutan Ngudi Makmur di sekitar kawasan Taman Nasional Gunung Merapi. Jurnal EKOSAINS, VI(1), 47-61.

Herawati, T., Widjayanto, N., Saharuddin, \& Eriyatno. (2010). Analisis respon pemangku kepentingan di daerah terhadap kebijakan hutan tanaman rakyat. Jurnal Analisis Kebijakan Kehutanan, 7(1), 13-25.

International Union for Conservation of Nature. (2003). Guidelines for management planning of protected area. (L. Thomas, J. Middleton \& A. Phillips. Eds.). Cambridge: IUCN.

Kartodihardjo, H. (2006). Ekonomi dan institusi pengelolaan hutan. Bogor: Institute for Development Economics of Agronomic and Rural Areas.

Kasper, W. S. M. (1998). Institutional economics: Social order and public policy. Cheltenham (UK): Edward Elgar.

Kementerian Kehutanan. Peraturan Menteri Kehutanan Nomor 29 Tahun 2013 Tentang Pedoman Pendampingan Pembangunan Kehutanan.

Kementerian Kehutanan. Peraturan Menteri Kehutanan Nomor 85 Tahun 2014 Tentang Tata Cara Kerja Sama Penyelenggaraan Kawasan Pelestarian Alam dan Kawasan Suaka Alam.

Lembaga Administrasi Negara. (2008). Negosisasi kolaborasi dan jejaring kerja modul pendidikan dan pelatihan kepemimpinan tingkat III. Jakarta: Lembaga Administrasi Negara.

Mulyana, D. (2006). Metode penelitian kualitatif. Bandung: PT Remaja Rosdakarya.

Nugroho, B., Sukardi, D., \& Widyantoro, B. (2012). Studi dan analisis peraturan perundangan terkait dengan pengelolaan pada hutan, 
hutan berbasis karbon, penyerapan karbon, stok karbon, dan produk ramah lingkungan. (Laporan Teknis). Jakarta: Kementerian Kehutanan RI dan ITTO.

Ostrom, E. (2005). Understanding institutional diversity. Princenton, New Jersey: Princenton University Press.

Pratidna G. (2014). Implementasi kebijakan model kampung konservasi taman nasional. Jurnal Ilmu Administrasi Negara, 12(4), 256-266.

Puspitojati, T., Darusman, D., Tarumingkeng, R. C., \& Purnama, B. (2012). Preferensi pemangku kepentingan dalam pengelolaan hutan produksi: Studi kasus di kesatuan pemangkuan hutan Bogor. Jurnal Analisis Kebijakan Kehutanan, 9(3), 190-204.

Reed, S.M., Graves, A., Dandy. N., Posthumus, H., Huback, K., Morris, J., Prell, C.H., Quin, C.H., Stringer, L.C. (2009). Who's in and why? A typology of stakeholder analysis methods for natural resources management. Journal of Environmental Management, 90(16), 1933-1949

Roslinda, E., Darusman, D., Suharjito, D., \& Nurrochmat, D.R. (2012). Analisis pemangku kepentingan dalam pengelolaan Taman Nasional Danau Sentarum Kabupaten Kapuas Hulu, Kalimantan Barat. Manajemen Hutan Tropika, XVIII(2), 78-85. https://doi. org/10.7226/jtfm.18.2.78

Sari, N., Noor, I., \& Prasetyo, W.Y. (2014). Pengembangan kapasitas kelembagaan pemerintah daerah dalam meningkatkan kualitas pelayanan perizinan terpadu (Studi pada Kantor Pelayanan dan Perizinan Terpadu
Kabupaten Kediri). Jurnal Administrasi Publik (JAP), 2(4), 634-640.

Schmid AA. (2004). Conflict and coorperation; Institutional and behavioral economics. New York: Willey-Blackwell.

Sepriyanto YD, Arkanudin, S. (2012). Pemberdayaan masyarakat di sekitar Balai Taman Nasional Gunung Palung Kecamatan Sukadana Kabupaten Kayong Utara: Studi kasus Desa Gunung Sembilan. PMIS-UNTAN Jurnal Tesis, 1-11.

Massiri, S.D. (2016). Keberlanjutan institusi kesepakatan konservasi masyarakat di Taman Nasional Lore Lindu Provinsi Sulawesi Tengah. (Disertasi). Bogor: Institut Pertanian Bogor.

Suporahardjo. (2005). Manajemen kolaborasi. Bogor: Pustaka latin.

Winara, A., \& Mukhtar, A. S. (2011). Potensi kolaborasi dalam pengelolaan Taman Nasional Teluk Cenderawasih di Papua. Penelitian Hutan dan Konservasi Alam, 8(3), 217-226.

Wollenberg, E., Edmunds, D., Buck, L., Fox, J., \& Brodt, S. (2005). Pembelajaran sosial dalam pengelolaan hutan komunitas. (Terjemahan oleh Suporahardjo). Bogor: Pustaka latin.

Wulandari, W., \& Sumarti, T. (2011). Implementasi manajemen kolaboratif dalam pengelolaan ekowisata berbasis masyarakat. Jurnal Transdisiplin Sosiologi, Komunikasi dan Ekologi Manusia, 5(1), 32-50. 